NASA Contractor Report 189187

AIAA-92-3123

\title{
Rocket Propulsion Research at Lewis Research Center
}

Virginia P. Dawson

The Winthrop Group, Inc.

Cambridge, Massachusetts

July 1992

Prepared for

Lewis Research Center

Under Contract NASW-3920

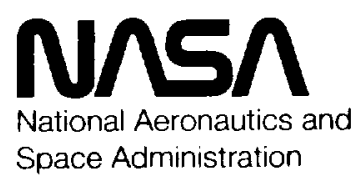

(NASA-CR-1:?1A7) ROCKET PROPULSITN

$192-30908$

RFSEAOCH AT LFWIS KESEAPCH CENTER

Final regort (Winthrop Group) $a p$

unclas

Space Administration

$63 / 80$

0104341 
$-7$

-... 


\title{
ROCKET PROPULSION RESEARCH AT LEWIS RESEARCH CENTER
}

\author{
Virginia P. Dawson \\ The Winthrop Group, Inc. \\ Cambridge, Massachussetts
}

\section{$\underline{\text { Abstract }}$}

A small contingent of engineers at NASA Lewis Research Center pioneered in basic research on liquid propellants for rockets shortly after World War II. Carried on through the 1950s, this work influenced the important early decisions made by Abe Silverstein when he took charge of the Office of Space Flight Programs for NASA. He strongly supported the development of liquid hydrogen as a propulsion fuel in the face of resistance from Wernher von Braun. Members of the Lewis staff played an important role in bringing liquid hydrogen technology to the point of reliability through their management of the Centaur Program. This paper demonstrates how the personality and engineering intuition of Abe Silverstein shaped the Centaur program and left a lasting imprint on the laboratory research tradition. Many of the current leaders of Lewis Research Center received their first hands-on engineering experience when they worked on the Centaur program in the 1960s.

\section{$\underline{\text { Introduction }}$}

Too often we forget the human element in the creation of technology. Laboratory research traditions, nurtured over a period of many years, as well as leadership are required to bring a complex technology to a point where it can be reliably used. In the development of liquid hydrogen as a propulsion fuel, both the laboratory research tradition and the vision of $A$ be Silverstein played a central role in encouraging basic research on liquid fuels during the 1950s at the NACA Lewis Flight Propulsion Laboratory. Silverstein's background in liquid hydrogen technology built at Lewis over a decade gave him confidence to champion the cause of liquid hydrogen in the face of strong arguments for conventional kerosene-based fuels. The success of the Centaur Program managed at Lewis proved his faith in liquid hydrogen. It also demonstrated the ability of men with backgrounds in laboratory research to manage large development programs.

\footnotetext{
*Present address: 3290 Glencairn Road, Cleveland, Ohio 44122.

Copyright (C) 1992 by the American Institute of Aeronautics and Astronautics, Inc. No copyright is asserted in the United States under Title 17, U.S. Code. The U.S. Government has a royalty-free license to exercise all rights under the copyright claimed herein for Governmental purposes. All other rights are reserved by the copyright owner.
}

\section{Early Liquid Hydrogen Research at Lewis}

Research on rocket fuels began at Lewis Laboratory during World War II. Late in the war, members of the Fuels and Lubricants Division carried out tests of solid propellants in four hastily constructed test stands. Although this work was officially terminated in 1945, research in rocket propulsion continued despite lack of official sanction. Members of the small rocket section, impressed by the V-2, studied German technical papers as well as those produced by the group under Frank Malina at the Jet Propulsion Laboratory. They decided to focus their investigations on the least studied area: that of liquid propellants. By 1948 , they had calculated the performance of a number of high energy fuels. They concluded that liquid hydrogen held greatest promise because of its high specific impulse. ${ }^{1}$

Commitment to liquid hydrogen among rocket pioneers had an impressive history. Konstantin Tsiolkovsky had recommended it as a rocket fuel in his "Treatise on Space Travel" in 1903. Hermann Oberth and Robert Goddard had also discussed its potential. In the United States a group at Ohio State University tested a rocket fueled by liquid hydrogen as early as 1945. But the technical problems in developing a rocket fueled by liquid hydrogen were formidable. Without laboratory facilities and a dependable supply, the study of liquid hydrogen had to be passed over in favor of fuels like hydrazine to be used with oxidizers like hydrogen peroxide, chlorine trifluoride, liquid oxygen, nitrogen tetroxide, and liquid fluorine. ${ }^{2}$

This situation began to change when Abe Silverstein became Chief of Research in 1949. He allowed the new rocket branch within the Fuels and Combustion Division more responsibility and visibility. He encouraged the group to establish criteria for propellant selection. The group was frustrated by their inability to verify their predictions by experiment. 
In 1951, possibly in response to intelligence reports of Russian advances in rocketry, the NACA authorized a formal Subcommittee on Rocket Engines within the Power Plants Committee. That same year Lewis Laboratory received its first formal appropriation for rocket research. However, the staff assigned to the rocket branch remained less than 3 percent of the laboratory's personnel. Experimental facilities, now supplemented by four larger test cells paid for out of laboratory operating funds, remained inadequate.

The following year the NACA rocket engine subcommittee, chaired by Maurice Zucrow, prodded the slow moving NACA headquarters to support funding of a $\$ 2.5$ million rocket propulsion laboratory for highenergy propellants, completed at Lewis in 1957. In 1952 the laboratory also purchased a hydrogen liquifier. By 1954, the rocket branch had developed the nation's first regeneratively cooled liquid hydrogen-liquid fluorine rocket with 5000 pounds of thrust.

However, the real breakthrough in terms of support came unexpectedly from aeronautics. The Air Force, interested in liquid hydrogen to fuel turbojet engines for high-altitude reconnaissance aircraft, funded an experimental test program at Lewis Laboratory called Project Bee.

This was exactly the kind of hands-on engineering project that Silverstien found most challenging. At last the work in high-energy propellants had gained full command of his attention. The project staff modified a B-57B bomber equipped with two Curtiss Wright J-65 engines so that one engine could burn either jet fuel or hydrogen. After extensive ground testing of the hydrogen system, it was flight tested over Lake Erie. The program resolved the questions of insulation, structure, and pumping of liquid hydrogen in flight.

Project Bee validated the work of the rocket branch. They received important experience in the handling and storage of liquid hydrogen that would later prove crucial when the laboratory later took charge of the development of the Centaur rocket. Silverstein, with Eldon Hall, wrote the final report: "Liquid Hydrogen as a Jet Fuel for High-Altitude Aircraft. ${ }^{3}$

\section{The Gathering Momentum of Space-Related Research}

In spring of 1957, the staff began to plan for a fall conference to evaluate propulsion systems. Proponents of space-related research urged Silverstein to allow them to include sessions on space flight and space propulsion systems, as well as more conventional systems such a turbojets and ramjets. Silverstein agreed to give them one afternoon session. With the imagination of many staff now sparked, research groups worked up sessions on liquid hydrogen, nuclear rockets, and space power systems.

The tension between the foot-dragging of NACA Headquarters and the gathering momentum of the Cleveland laboratory toward space-related research mounted in September when representatives from headquarters visited the laboratory to evaluate its rehearsal for the finely orchestrated NACA Triennial Inspection. The theme of the inspection was to be a celebration of the tenth anniversary of the X-1, the first aircraft to fly faster than the speed of sound. ${ }^{4}$

Unlike the more specialized conference, NACA Inspections were intended to convey the laboratory's work to lay people, a group made up largely of politicians and industry executives. At the "Stop," at the new rocket test facility a staff member proudly showed the NACA Executive Secretary, John Victory, the huge new scrubber, part of the silencing and exhaust gas disposal system. During the prepared talk, Victory bristled when he heard references to space. Always on the lookout for anything that might offend potential Congressional sponsors, he ordered all references to space deleted from the presentations. ${ }^{5}$

The intended celebration of 10 years of supersonic flight caught the NACA looking backwards. On October 4 the question of whether to discuss space-related work was moot. Between the rehearsal and the actual inspection, the Soviet Union launched Sputnik. Suddenly Chuck Yaeger's dramatic breaking of the sound barrier seemed like ancient history. Victory's earlier resistance to references to space put the conservative attitudes of headquarters in sharp relief. When the inspection began several days later, Lewis engineers could unveil with impunity their work on chemical rockets and even more visionary space propulsion systems.

The presentations on high-energy rocket propellants were the highlight of the inspection. Participants could admire a liquid-hydrogen/liquid-oxygen rocket engine capable of 20,000 pounds of thrust. After years of stubborn advocacy, the lonely visionaries in the rocket branch found themselves beseiged by their colleagues in air-breathing propulsion systems for briefings on rocket fundamentals.

The laboratory reserved its most detailed consideration of its work in space propulsion for the classified NACA-Industry Conference, held the following month. Once again the rocket researchers held center stage. The presentation by John Sloop, A.S. Boksenbom, S. Gordon, R.W. Graham, P.M. Ordin, and A.O. Tischler discussed propulsion requirements for specific missions, including surface-to-surface missiles, Earth satellites, and Moon missions. They considered both circumnavigation 
of the Moon and an ambitious Moon landing, using an orbiting Earth satellite as a base, probably the first detailed discussion of a Moon landing in NACA-NASA literature. Frank E. Rom, Eldon W. Sams, and Robert E. Hyland's paper "Nuclear Rockets," and the paper "Satellite and Space Propulsion Systems," by W.C. Moeckel, L.V. Baldwin, R.E. English, B. Lubarsky, and S.H. Maslen, were equally visionary. ${ }^{6}$

\section{Planning for Liquid Hydrogen Upper Stage Rockets}

Shortly after NASA's formal creation in July 1958, Silverstein set up a committee to define NASA's propulsion needs. By August this committee had concluded that, for launch vehicles requiring high-performance upper stages, the liquid-hydrogen/liquid-oxygen combination appeared to show the greatest promise. The consensus reached in this NASA committee coincided with the acceptance by the Advanced Research Projects Agency (ARPA) of a proposal by Krafft Ehricke of General Dynamics/Astronautics to develop a liquid hydrogen upper stage for the Atlas missile. Pratt \& Whitney agreed to undertake the development of the RL-10 engine. In July 1959 these programs were transferred to NASA. ${ }^{7}$

In December 1959 Silverstein assembled a committee to evaluate the proposed Saturn vehicle. The committee's specific charge was to decide on the configuration of the upper stages for Saturn. To Silverstein a liquid hydrogen upper stage seemed particularly attractive because it could produce approxomately 40 percent more payload per pound of lift-off weight than conventional propellants.

Project Bee had convinced Silverstein that hydrogen could be used safely. Von Braun, however, did not share Silverstein's sanguine view of hydrogen. In Silverstein's view:

The von Braun team was apparently willing to take on the difficulties of the 15 million-pound thrustbooster stage rather than the hazards which they contemplated in the use of hydrogen as a fuel. The Lewis team of NASA had pioneered in the use of hydrogen oxygen and had operated small rocket engines with hydrogen as a fuel for 10 years prior to the time of the decision on Saturn. We had become very accustomed to its use and its safety.

Silverstein came to the meeting of the Saturn Evaluation Committee armed with data from a NASA study on the feasibility of liquid hydrogen put together by Eldon Hall, Adelbert O. Tischler, and Abe Hyatt. He argued that conventional upper stages were too heavy for the required payload. For a week the NACA team and the von Braun group debated, until von Braun at last capitulated. "What led him to this final decision, I'll never know," Silverstein remarked. He believed it was nevertheless the technically correct decision. This decision gave the United States the edge over the Soviet Union in the race to the Moon: "I believe that the decison to go with hydrogen-oxygen in the upper stages of the Saturn $\mathrm{V}$ was the significant technical decision that enabled the United States to achieve the first manned lunar landing. The Russian effort to accomplish this mission without high-energy stages was doomed to failure. ${ }^{n 9}$

After this meeting the development of Centaur and Saturn $\mathrm{V}$ became inextricably intertwined. As an intermediate step NASA intended to use the Atlas/Centaur to launch Surveyor, an unmanned probe to soft land on the moon. Data from Surveyor was vital for determining the composition of the Moon's surface prior to landing human beings there. Centaur had the added onus of proving the feasibility of liquid hydrogen prior to using it to power Saturn's upper stages.

\section{Centaur and its Vicissitudes}

In July 1960 the Centaur Program was assigned to Marshall Space Flight Center where it languished in the shadow of the Saturn project. By September 1962 it was dangerously close to cancellation. Fortunately, at that point Edgar Cortright, Deputy Director of the Office of Space Sciences at NASA Headquarters, remembered the keen interest in liquid hydrogen at Lewis where he had spent the early part of his career. He asked Silverstein, who had recently become Director of Lewis Research Center, to come to Headquarters. He discussed a letter that his boss, Homer D. Newell, had received from Wernher von Braun. Von Braun argued thast NASA should cancel the Centaur Program. It is not clear exactly why von Braun resisted the use of liquid hydrogen as a rocket fuel. According to John Sloop who had a position at Headquarters during the early NASA years, structural concerns were paramount. To offset the low density of liquid hydrogen fuel, the design of Centaur required bulky, thin-walled structures. Sloop wrote:

The von Braun team simply did not trust Karl Bossart's thin-wall, pressure-stabilized tanks first used by General Dynamics for Atlas and then for Centaur. Centaur had only a thin, common wall dividing the fuel and oxidant tanks, and at one time von Braun came to Washington to push a design change that separated the two tanks, a change that would delay the stage development. His request was denied by Robert Seamans. I believe that these structure concerns outweighed von Braun's concerns about using liquid hydrogen. 10 
Von Braun recommended that the Saturn C-1/ Agena D launch vehicle replace Centaur. The Jet Propulsion Laboratory (JPL), in charge of the Surveyor Program since 1960, concurred. Von Braun convinced JPL that Centaur could not be devleoped in time to provide the necessary knowledge of the Moon's surface prior to the Apollo landing. In a letter to Newell, Brian Sparks, Deputy Director of JPL, cited "the deplorable situation in the current Centaur program ${ }^{n}$ in support of cancellation. The development of a new space vehicle fueled by liquid hydrogen required too much time. To compete with the "doggedly determined effort of the Soviets," the existing technology of kerosene-based fuels had a greater chance of success. He wrote:

The Office of Manned Space Flight has said that data from a soft-landed Surveyor in 1964 or 1965 would be an invaluable aid in Apollo design, and high-quality reconnaissance data from a lunar Orbiter in 1968 is desirable for Apollo flight planning. These objectives could be achieved on a C-1/Agena D but not on Centaur in this time scale. $^{11}$

On May 8, 1962, 54 seconds after liftoff, the Centaur portion of an Atlas-Centaur launch vehicle had exploded. Investigation revealed that an internal NASA report had predicted this failure. Studies indicated that the insulation panels could not withstand the anticipated pressure loads.

Moreover, three explosions of engines on Pratt \& Whitney's test stands at its Research and Development Center in Florida had resulted in both delay and $\$ 1.2$ million worth of damage to the RL-10 engine. The investigation concluded that these were preventable accidents. ${ }^{12}$

Differences in engineering backgrounds and loyalties between Marshall and General Dynamics had created an adversarial relationship. In the view of historians Richards and Powell:

A large part of the problem was due to conflict between Marshall, with their Army origins and main interest in the Saturn launcher family, and the Convair [General Dynamics] and USAF managers with their Atlas background. The entire programme came near to cancellation as initial attempts to redesign the areas that failed in flight led to such a large weight increase that the Surveyor payload could no longer be carried. It was only the absence of any alternative that saved the programme, and a reserve plan to use a Titan 2 booster instead of the Atlas was suggested to overcome the weight problem. ${ }^{13}$

\section{Centaur Comes to Lewis}

In September 1962 the choice at Headquarters appeared to be either to drop the Centaur program entirely or find another NASA center willing to take over its management. When Edgar Cortright asked Silverstein if Lewis wanted the Centaur program, Silverstein did not hesitate, even though project management on the scale of the Centaur program was new to Lewis. In October Marshall sent plane loads of boxes containing books, drawings, spare parts lists, and unsatisfied change orders. They were unceremoniously dumped on the hanger apron at Lewis.

Silverstein asked David J. Gabriel, a Lakewood native with a mechanical engineering degree from the University of Akron, to take charge of the Centaur Project Office with Cary Nettles as his Deputy. E.F. Baehr, Jack Brun, Russel Dunbar, Elmo Farmer, William Goette, Ed Jonash, John Quitter, C.B. Wentworth, and R.A. Yaeger, all seasoned Lewis staff, formed the core of the project. But Silverstein did not limit Centaur participation to people with already proven talent. Some of the new hires during the early Apollo period cut their engineering teeth on Centaur's many problems.

To strengthen the hand of Lewis in technical management of the project Silverstein made the former subcontractors of General Dynamics, associate contractors. They reported directly to Lewis staff rather than managers at General Dynamics. An exception was the development of the RL-10 engine which continued to be supervised by Marshall (until 1966 when this program was also moved to Lewis). Lewis engineers began to develop strong ties with Pratt \& Whitney's design team in the early 1960s. They collaborated on the design of the RL-10's injector. Pratt \& Whitney engineers also used studies on regenerative cooling carried out under Robert Graham in the Cryogenic Heat Transfer Section. ${ }^{14}$

Silverstein himself made the key technical decision: to initially make Centaur a single burn mission. This would simplify the technical problems and save weight until the launch vehicle was operational. As originally conceived by the team at General Dynamics, Centaur was to have a multiple burn capability. After Centaur was fired, it would reach a parking orbit, shut down, coast to a predetermined point in the orbit, then the engines would be relit. Silverstein decided to make the early launches of Centaur a direct shot. That way the cosst phases could be eliminated.

There were many advantages to a direct shot. A single burn would save weight because some of the 
systems could be eliminated and the reliability of the vehicle would be greatly enhanced. For example, in order to assure that the pumps were cold enough to prevent cavitation, they were chilled with liquid helium to between $4-6^{\circ}$ above absolute zero. By making the initial flights direct shots, the question of how much chill down the second burn required could be deferred.

They could also put off the question how to manage the slosh of the propellants in the tank. Before the first burn, the tank is full and the vehicle is accelerating. But in the parking orbit before the second burn, the propellants get hot and the gas has to be vented. If the propellants are sloshing, liquid may get into the vent. The question of baffles to dampen the slosh posed another technical problem. Potentially, by simplifying the mission, it could be accomplished in less time, since so many new systems did not need to be designed.

Although the contractors for Centaur and Surveyor-General Dynamics and Space Technology Laboratories-were at first skeptical, they were cooperative in helping to work out a new trajectory. With a direct shot, the windows within which launches could take place was far more limited, but nevertheless feasible.

The Centaur team worked at a frenzied pace, commuting to California to oversee work by General Dynamics and to Cape Canaveral to prepare for launches. The first several single burn missions demonstrated correctness of Silverstein's approach culminating in the flawless landing of Surveyor 1 on the Moon in May 1966 and the transmission of the first TV pictures of the Moon's surface. With each mission they were able to solve new problems. In October 1966 they achieved the first restart of a liquid-hydrogen/liquidoxygen engine in space. Similar success with hydrogen in the upper stages of the Saturn V proved von Braun's pessimistic attitude toward liquid hydrogen unjustified. He autographed a picture of the launch of Apollo 4 on November 9, 1967: "To Abe Silverstein whose pioneering work in liquid hydrogen technology paved the way to today's sucesss." 15

The Centaur story also demonstrates the importance of technical leadership. Silverstein epitomized the breed of engineer Arthur Squires has described as a "maestro of technology" - someone who is thoroughly familiar with the technology, who knows his staff well enough to put together the right team for a specific task, and who protects them from the aggravations of unnecessary bureaucracy. ${ }^{16}$ No doubt Silverstein could be gruff, tactless, and impatient with mediocrity, but his engineering colleagues respected him and recognized his leadership ability. In a New York Times interview, a NASA colleague called Silverstein a genius- "not in terms of invention and discovery but in his breadth of comprehension of technical matters and his remarkable facility for getting down to the fundamentals in any field he tackles." 17

The winning combination of leadership, commitment and teamwork was a product of Lewis's unique engineering culture. Years of research experience with liquid hydrogen had convinced Silverstein of its promise as a rocket fuel. He had confidence that the team he had assembled could overcome Centaur's many development problems. Such was his personal commitment to the program that it came to be regarded as "Abe's Baby." The Centaur program provided valuable hands-on engineering experience to recent engineering graduates. To this day, staff who began at Lewis during the early Apollo years, many of whom are now in upper management positions, look back on the Centaur program as a formative influence on their careers. The Centaur program demonstrated the ability of the laboratory to build on its research experience. The center's management of a large-scale development program succeeded because it had the winning combination of people with knowledge, confidence, and most importantly leadership skills. Silverstein left as one of his legacies a trained cadre of individuals who continue to believe in the synergism between a strong research tradition and large-scale development projects.

\section{Acknowledgments}

The history of research on liquid hydrogen discussed in the early parts of my paper can be found in John Sloop's Liquid Hydrogen as a Propulsion Fuel, 19451959. He also graciously assisted me by sending me some of his personal papers when I was completing Engines and Innovation: Lewis Laboratory and American Propulsion Technology. For the present paper I also interviewed some of the participants of the Centaur program. I wish to thank Kenneth Baud, William Goette, Ned Hannum, John Kramer, Frank Spurlock, William Tabata, and Arthur Zimmerman. 
1.R.O. Miller and P.M. Ordin, "Theoretical Performance of Rocket Propellants Containing Hydrogen, Nitrogen, and Oxygen," NACA RM E8A30, 1948, cited in John Sloop, Liquid Hydrogen as a Propulsion Fuel, 1945-1959, NASA SP-4404, (Washington, D.C., U.S. Government Printing Office, 1978), p. 80.

2.Sloop, Liquid Hydrogen, p. 75.

3.Abe Silverstein and Eldon W. Hall, "Liquid Hydrogen as a Jet Fuel for High-Altitude Aircraft," NACA RM E55 C28a, April 15, 1955. See also Sloop, Liquid Hydrogen, pp. 102-107.

4. "10 Years After X-1: Supersonic Anniversary Puts Flight Laboratory Here in Spotlight, "Cleveland Plain Dealer Magazine, October 6, 1957.

5.Sloop, Liquid Hydrogen, pp. 90-91.

6.Papers of the NACA 1957 Flight Propulsion Conference were originally classified as part of NASA TM X-61622 [1960]. It was later published in two parts. NASA TM X-67368 [1971] contains six papers on airbreathing propulsion systems, three on rocket systems, including "Propellants," by E.A. Fletcher, H.W. Douglass, R.J. Priem, and G. Vasu; "Turbopumps for High-Energy Propellants," by Ambrose Ginsburg, Ward W. Wilcox, and David G. Evans; and "Performance and Missions," by J.L. Sloop, A.S. Boksenvom, S. Gordon, R.W. Graham, P.M. Ordin, and A.O. Tischler. The second set of papers were published as TM X-61622 [1972] and include Wolfgang Moeckel, L.V. Baldwin, Robert English, Bernard Lubarsky, and Steve Maslen, "Satellite and Space Propulsion Systems," Paul G. Johnson, James W. Miser, and Roger L. Smith, "Nuclear Logistic Carrier," and Frank E. Rom, Eldon W. Sams, and Robert E. Hyland, "Nuclear Rockets."

7.For the technical history of Centaur, see G.R. Richards and Joel W. Powell, "The Centaur Vehicle," Journal of the British Interplanetary Society 42(1989): 99-120.

8.Abe Silverstein, "How It All Began." Speech at Kennedy Space Center Writers Conference, Cocoa Beach, FL, Sept. 1-3, 1977 NASA History Office, Lewis Research Center file.
9.Silverstein, Ibid.

10.John Sloop, personal communication to Virginia Dawson, September 5, 1989. See also: Richard E. Martin, "The Atlas and Centaur 'Steel Balloon' Tanks: A Legacy of Karel Bossart," 40th International Astronautical Congress paper, published by American Institute of Aeronautics and Astronautics, Inc., 1989.

11.Brian Sparks to Homer Newell, September 21, 1962, Atlas-Centaur Launch Vehicle file, NASA History Office, Washington, D.C.

12. "Review of the Atlas-Centaur Launch Vehicle Development Program," Report to the Committee on Science and Astronautics, House of Representatives, March 1963, Atlas-Centaur Launch Vehicle file, NASA History Office, Washington, D.C.

13.G.R. Richards and Joel W. Powell, "The Centaur Vehicle," Journal of the British Interplanetary Society 42(1989): 103.

14.Two classic papers on hydrogen heat transfer that grew out of the work with Pratt \& Whitney are Robert C. Hendricks, Robert W. Graham, Yih-yun Hsu, and Robert Friedman, "Experimental Heat Transfer and Pressure Drop of Liquid Hydrogen Flowing Through a Heated Tube," NASA TN D-765, May 1961; "Experimental Heat Transfer Results for Cryogenic Hydrogen Flowing in Tubes at Subcritical and Supercritical Pressures to 800 psi Absolute," NASA TN D-3095, March 1966.

15. See illustration, Virginia Dawson, Engines and Innovation: Lewis Laboratory and American Propulsion Technology, NASA-SP 4306, (Washington, D.C.: U.S. Gov. Printing Office, 1991), p. 194.

16. Andrew Squires, The Tender Ship: Government Management of Technological Change, (Boston: Birkhauser, 1986).

17.New York Times, March 12, 1960, Silverstein biography file, NASA History Office, Washington, D.C. 



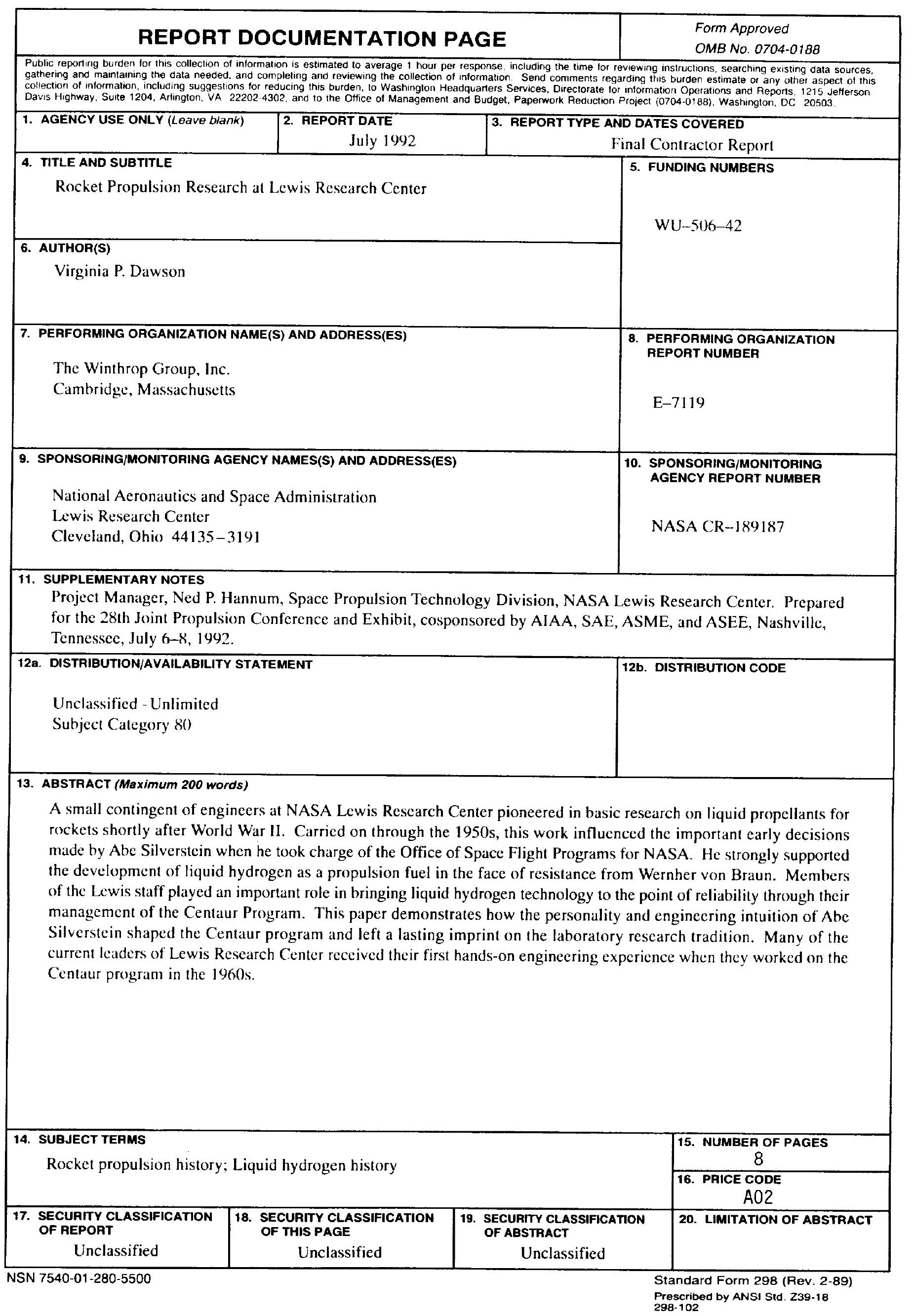


National Aeronautics and

Space Administration

Lewis Research Center

Cleveland, Ohio 44135

Official Business

Penaity for Private Use $\$ 300$

FOURTH CLASS MAIL

ADDRESS CORRECTION REQUESTED

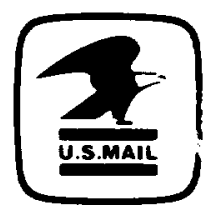

Postrgeand Fees Pard

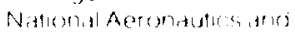

Spitre Adminstratum

NASA 45 
